\title{
MULTIPLICAÇÃO DE Pseudomonas fluorescens EM TEMPERATURAS DE REFRIGERAÇÃO E SEU POTENCIAL PROTEOLÍTICO
}

\section{Multiplication of Pseudomonas fluorescens in refrigeration temperatures and its proteolytic potential}

\author{
Elisângela Michele Miguel ${ }^{1}$, Denise Sobral ${ }^{1}$, Gisela de Magalhães Machado Moreira ${ }^{1}$, \\ Renata Golin Bueno Costal, Vanessa Aglaê Martins Teodoro², \\ Antônio Fernandes de Carvalho ${ }^{3}$
}

\begin{abstract}
RESUMO
A multiplicação de estirpes de Pseudomonas fluorescens 07A e $041 \mathrm{em}$ condições de refrigeração foi avaliada neste trabalho, bem como seu potencial proteolítico usando-se ágar-leite e azocaseína como substrato. Foi possível observar a multiplicação dos isolados nas temperaturas de refrigeração, sendo que ocorreu um aumento da multiplicação na medida em que se aumentou a temperatura e o período de estocagem. A atividade proteolítica dos isolados foi demonstrada pelo ágar-leite, sendo que a do isolado 07A foi superior à de 041, o que também foi observado pela técnica de azocaseína. Esse resultado se deve à variabilidade genética entre os microrganismos psicrotróficos e a expressão de suas enzimas proteolíticas. A legislação brasileira preconiza o uso de temperaturas de refrigeração para o armazenamento do leite cru na propriedade rural e no estabelecimento processador. Entretanto, as temperaturas estabelecidas não inibem a multiplicação de microrganismos psicrotróficos. Portando, é imprescindível assegurar a adoção de boas práticas de produção para evitar contaminações, além do controle efetivo do tempo e da temperatura de estocagem do leite cru para se evitar a sua contaminação durante a produção e não comprometer a sua qualidade e de seus derivados.
\end{abstract}

Palavras-chave: psicrotrófico; proteólise; leite cru; substrato.

1 Empresa de Pesquisa Agropecuária de Minas Gerais, Instituto de Laticínios Cândido Tostes, Rua Tenente Luiz de Freitas, 116, Santa Terezinha, 36045-560, Juiz de Fora, MG, Brasil. E-mail: elisangelamichele@ epamig.br

2 Universidade Federal de Juiz de Fora, Faculdade de Medicina Veterinária, Juiz de Fora, MG, Brasil.

3 Universidade Federal de Viçosa, Departamento de Tecnologia de Alimentos, Viçosa, MG, Brasil.

* Autor para correspondência.

Recebido / Received: 06/02/2019

Aprovado / Approved: 16/04/2019 


\begin{abstract}
The multiplication of Pseudomonas fluorescens strains 07A and 041 under refrigeration conditions was evaluated in this work, as well as its proteolytic potential using milk agar and azocaseína as substrate. It was possible to observe the multiplication of the isolates at the cooling temperatures, and an increase in multiplication occurred as the temperature and the storage period were increased. The proteolytic activity of the isolates was demonstrated by milk agar, and that of isolate $07 \mathrm{~A}$ was higher than that of 041 , which was also observed by the azocasein technique. This result is due to the genetic variability between psychrotrophic microorganisms and the expression of their proteolytic enzymes. Brazilian legislation recommends the use of refrigeration temperatures for storage of raw milk in the rural property and in the processing establishment. However, established temperatures do not inhibit the multiplication of psychrotrophic microorganisms. Therefore, it is essential to ensure the adoption of good production practices to avoid contamination, as well as the effective control of the time and temperature of storage of raw milk to avoid contamination during production and thus not compromise its quality and its derivatives.
\end{abstract}

Keywords: psychrotrophic; proteolysis; raw milk; substrate.

\section{INTRODUÇÃO}

O leite, por ser considerado um alimento completo em nutrientes, torna-se um meio de cultura ideal para a multiplicação da maioria dos microrganismos encontrados na natureza e, por isso, está susceptível à deterioração. Portanto, há a necessidade de utilização de métodos adequados de conservação para minimizar o desenvolvimento da microbiota contaminante e possibilitar a oferta de produtos com qualidade e segurança (ZENI et al., 2013).

A regulamentação da produção de leite no Brasil tem passado por mudanças importantes desde a aprovação da Instrução Normativa $n^{\circ} 51$ (IN 51/2002), em 18 de setembro de 2002 (BRASIL, 2002), com destaque à refrigeração do leite na propriedade rural e seu transporte granelizado. A IN 51/2002 foi, posteriormente, alterada pela Instrução Normativa $n^{\circ} 62$ (IN 62/2011) de 29 de dezembro de 2011 (BRASIL, 2011) e, recentemente, em 26 de novembro de
2018, o Ministério da Agricultura, Pecuária e Abastecimento (MAPA) fixou novas regras para a produção de leite no país. A Instrução Normativa $n^{\circ} 76$ (IN 76/2018) (BRASIL, 2018a) aprova os padrões de identidade e qualidade do leite cru refrigerado e a Instrução Normativa $n^{\circ} 77$ (IN 77/2018) (BRASIL, 2018b) estabelece os critérios e procedimentos para a produção, acondicionamento, conservação, transporte, seleção e recepção do leite cru em estabelecimentos registrados no serviço de inspeção oficial, além de revogar todas as normas anteriores que dispõem contrariamente ao assunto. Essas normas apresentam alterações importantes nas obrigatoriedades em relação à temperatura de recebimento do leite cru na indústria (BRASIL, 2018a; BRASIL, 2018b), além de padrões microbiológicos do leite após a sua obtenção na propriedade rural e na indústria, antes de seu processamento (BRASIL, 2018a).

O leite cru deve ser mantido refrigerado na propriedade rural em tanques de refrigeração por expansão direta (individual 
ou comunitário) e atingir a temperatura igual ou inferior a $4{ }^{\circ} \mathrm{C}$ em até 3 horas. O tempo entre as coletas de leite nas propriedades rurais pela indústria não deve ser superior a 48 horas. O leite deve ser coletado em caminhões providos de tanques isotérmicos e encaminhado aos estabelecimentos industriais para o processamento nos quais deve atingir a temperatura máxima de $7{ }^{\circ} \mathrm{C}$, podendo, excepcionalmente, ser recebido a $9^{\circ} \mathrm{C}$ (BRASIL, 2018a; BRASIL, 2018b).

O resfriamento do leite após a ordenha na fazenda e o transporte a granel são importantes medidas que visam à preservação da qualidade da matéria prima e, consequentemente, a diminuição da deterioração do produto, tendo em vista que temperaturas de refrigeração inibem a multiplicação de microrganismos mesofílicos e, assim, diminuem a ação acidificante deste grupo. Entretanto, tais temperaturas selecionam os microrganismos psicrotróficos os quais são capazes de se multiplicar em temperatura de refrigeração, independentemente da sua temperatura ótima de multiplicação (ZENI et al., 2013; NÖRBERG et al., 2010; NÖRBERG et al., 2009; SØRHAUG; STEPANIAK, 1997). Esses microrganismos são capazes de produzir proteases termoestáveis que reduzem a qualidade do leite e comprometem a produção de derivados com diminuição da qualidade e consequente limitação da vida-de-prateleira desses produtos (PINTO et al., 2016; MARTINS et al., 2015; PINTO et al., 2014, ZENI et. al., 2013; BAGLINIÈRE et al., 2012, NÖRBERG et al., 2009), o que causa prejuízos para a indústria laticinista (PINTO et al., 2014; ZENI et. al., 2013; NÖRBERG et al., 2010; NÖRBERG et al., 2009; SØRHAUG; STEPANIAK, 1997).

A população de microrganismos psicrotróficos no leite cru pode alcançar altas concentrações quando ele é obtido em condições precárias de higiene, sendo as bactérias do gênero Pseudomonas encontradas com maior frequência em leite e derivados mantidos sob refrigeração (SAMARŽIJA et al., 2012; PERIN et al., 2012; ZHANG; LV, 2014; MAHROUS; MOUSA, 2012; RAAS et al., 2011, NÖRBERG et al., 2010). Esse gênero abrange espécies que se caracterizam por apresentar um curto tempo de geração a temperaturas de refrigeração (SAMARŽIJA et al., 2012; SØRHAUG; STEPANIAK, 1997).

Dentre as espécies de Pseudomonas, $P$. fluorescens constitui a de maior importância por produzir proteases termoestáveis que hidrolisam a caseína e diminuem o rendimento industrial e a qualidade sensorial dos produtos lácteos (MARTINS et al., 2015; BAGLINIÈRE et al., 2013; BAGLINIÈRE et al.; 2012; ZHANG; LV, 2014; MAHROUS; MOUSA, 2012; NÖRBERG et al., 2010).

As enzimas proteolíticas produzidas por bactérias psicrotróficas podem resultar em vários problemas tecnológicos para a indústria laticinista, como a instabilidade do leite ao calor, a gelificação do leite UHT, a ocorrência de sabores e odores indesejáveis (PINTO et al., 2016; PINTO et al., 2014, ZENI et al., 2013; BAGLINIÈRE et al., 2013; BAGLINIÈRE et al., 2012; SAMARŽIJA JA et al., 2012; ZHANG; LV, 2014; NÖRBERG et al., 2010; SØRHAUG; STEPANIAK, 1997) e a redução de rendimento na produção de queijo (ZHANG; LV, 2014).

Tendo em vista a importância de microrganismos psicrotróficos na cadeia produtiva do leite, bem como a proteólise causada em leite cru refrigerado e de seus derivados, o objetivo deste trabalho foi avaliar a multiplicação de isolados de $P$. fluorescens em temperaturas de refrigeração, bem como o potencial proteolítico desses microrganismos.

\section{MATERIAL E MÉTODOS}

Os microrganismos utilizados neste estudo foram os isolados psicrotróficos Pseudomonas fluorescens $07 \mathrm{~A}$ e 041 isoladas 
por Pinto (2004), gentilmente cedidas pelo Laboratório de Microbiologia de Alimentos do Departamento de Microbiologia da Universidade Federal de Viçosa, UFV.

\section{Curva de Multiplicação de P. fluorescens 07A e 041 em Leite Desnatado Reconstituído- LDR $12 \%(\mathrm{~m} / \mathrm{v})$}

A multiplicação dos isolados $P$. fluorescens 07A e 041 em Leite Desnatado Reconstituído (LDR) às temperaturas de refrigeração foi monitorada durante 10 dias. Os isolados foram ativados em caldo LDR, a $25{ }^{\circ} \mathrm{C}$ por 24 horas por duas vezes. Após este período, foram realizadas diluições decimais e plaqueamento em Ágar Padrão para Contagem (PCA) a cada 24 horas de incubação às temperaturas de 4,7 e $10^{\circ} \mathrm{C}$ pela técnica de micro-gotas (SILVA et al., 2007).

\section{Avaliação da Atividade Proteolítica dos Isolados de $P$. fluorescens 07A e $041 \mathrm{em}$ Ágar-leite}

Os isolados foram ativados em caldo Luria-Bertani (LB), a $21{ }^{\circ} \mathrm{C}$ por 24 horas por duas vezes. Em seguida, foram inoculadas mediante método de micro-gotas, descrito em Silva et al. (2007) em placas de Petri contendo ágar-leite (meio para contagem padrão em placas acrescido de $10 \%$ de LDR $10 \% \mathrm{~m} / \mathrm{v}$ ) e incubadas a $21^{\circ} \mathrm{C}$ por 24 horas e também por 7 dias a $7{ }^{\circ} \mathrm{C}$. A atividade proteolítica foi evidenciada pela formação de halo translúcido ao redor da colônia. Este experimento foi realizado em três repetições.

\section{Avaliação da Atividade Proteolítica dos Isolados de P. fluorescens 07A e $041 \mathrm{em}$ Azocaseína}

A metodologia foi realizada segundo Nörberg et al. (2010) utilizando-se azocaseína como substrato. As culturas estocadas em
Caldo Infusão Cérebro e Coração (BHI) foram ressuspendidas em $\mathrm{BHI}$ e incubadas a $30{ }^{\circ} \mathrm{C}$ por 24 horas. Após este período, foram inoculadas em frascos contendo 50 $\mathrm{mL}$ de meio mineral $\left(\mathrm{NaCl} \mathrm{0,5} \mathrm{g} / \mathrm{L} ; \mathrm{K}_{2} \mathrm{HPO}_{4}\right.$ $\left.0,4 \mathrm{~g} / \mathrm{L} ; \mathrm{KH}_{2} \mathrm{PO}_{4} 0,3 \mathrm{~g} / \mathrm{L}\right)$ e caseína $10 \mathrm{~g} / \mathrm{L}$ com $\mathrm{pH}$ ajustado para 7,0. Os frascos foram incubados à temperatura de $30{ }^{\circ} \mathrm{C}$ por 72 horas em agitador orbital com $120 \mathrm{rpm}$. Após o período de incubação, as amostras foram centrifugadas a $10.000 \mathrm{~g}$ por 5 minutos, com intuito de separar a biomassa do sobrenadante o qual foi utilizado para a análise da atividade proteolítica. Para isso, foi adicionado a $100 \mu \mathrm{L}$ do sobrenadante $100 \mu \mathrm{L}$ de solução $0,1 \mathrm{~g} / \mathrm{mol}$ de fosfato de sódio $\mathrm{pH} 7,0$ e $100 \mu \mathrm{L}$ de azocaseína a $10 \mathrm{mg} / \mathrm{mL}$. A mistura foi incubada em banho-maria a $37^{\circ} \mathrm{C}$ por 60 minutos. A reação foi interrompida com a adição de $500 \mu \mathrm{L}$ de Ácido Tricloroacético 30\% (TCA) e centrifugada a $10.000 \mathrm{~g}$. Então, a $800 \mu \mathrm{L}$ do sobrenadante, foram adicionados $200 \mu \mathrm{L}$ de $\mathrm{NaOH}$ 1,8 mol/L. A absorbância foi medida no espectrofotômetro a $420 \mathrm{~nm}$ (NanoDrop ND-1000 Spectrophotometer).

Paralelamente, foi feito o controle contendo todos os reagentes, exceto a amostra. $\mathrm{O}$ aumento da absorbância em 0,01 corresponde a uma unidade enzimática. Este experimento foi realizado em 20 repetições.

\section{Análises Estatísticas}

As análises estatísticas foram realizadas com o auxílio do programa MINITAB - versão 14 (MINITAB INC., 2003) e os resultados foram submetidos à análise de variância (ANOVA), bem como à comparação de médias pelo Teste de Tukey, a 5\% de probabilidade. 


\section{RESULTADOS E DISCUSSÃO}

Multiplicação de $P$. fluorescens 07 A e 041 às temperaturas de refrigeração de $4,7 \mathrm{e}$ $10{ }^{\circ} \mathrm{C}$.

Durante o monitoramento da multiplicação de $P$. fluorescens 07A e 041 em
LDR 12\% (m/v), observou-se um comportamento semelhante, uma vez que ambas são proteolíticas e isoladas do leite cru refrigerado. $\mathrm{O}$ resultado da multiplicação dos isolados pode ser visualizado nas Figuras 1 e 2 .

De acordo com os resultados apresentados, foi possível observar que houve a

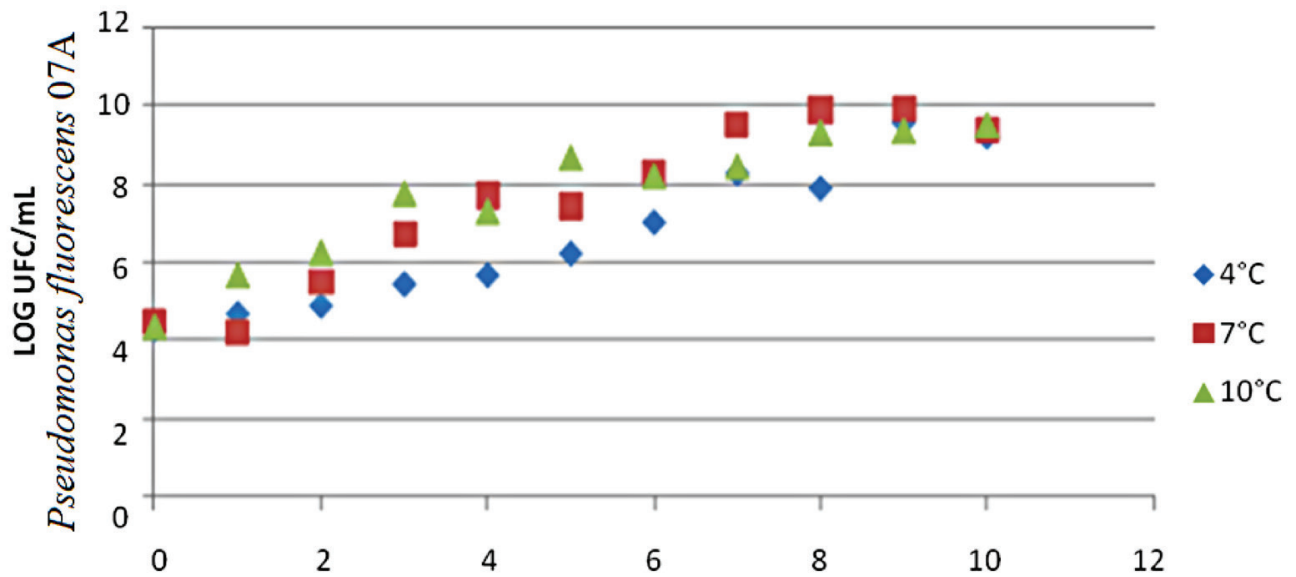

Figura 1 - Multiplicação do isolado $P$. fluorescens $07 \mathrm{~A}$ às temperaturas de 4,7 e $10{ }^{\circ} \mathrm{C}$, durante 10 dias de estocagem

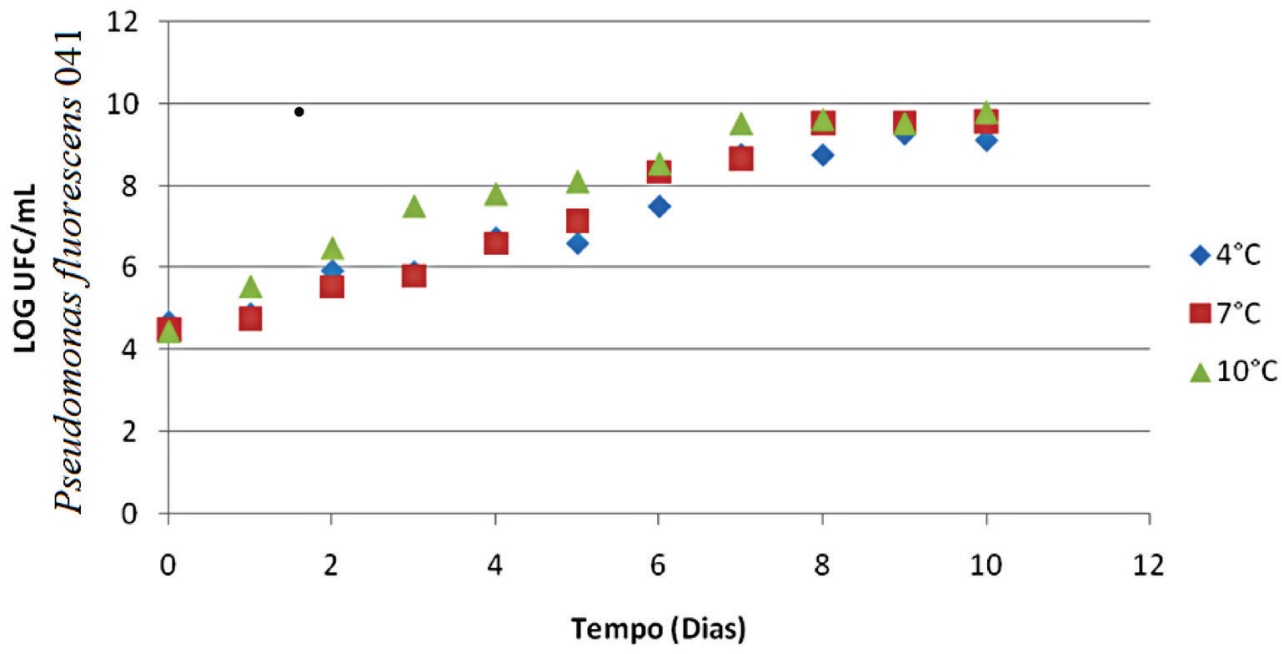

Figura 2 - Multiplicação do isolado $P$. fluorescens 041 às temperaturas de 4 , 7 e $10^{\circ} \mathrm{C}$, durante 10 dias de estocagem 
multiplicação dos isolados de P. fluorescens 07A e 041 nas três temperaturas durante o período de estocagem, não apresentando diferença significativa entre os isolados $(\mathrm{p}>$ $0,05)$. Além disso, ocorreu um aumento da multiplicação na medida em que se aumentou a temperatura e o período de estocagem, havendo diferença significativa entre as temperaturas de 4 e $10{ }^{\circ} \mathrm{C}(\mathrm{p}<0,05)$, sem diferir, porém, entre as temperaturas de 4 e $7{ }^{\circ} \mathrm{C}(\mathrm{p}>0,05)$. Os isolados apresentaram comportamento semelhante em relação à multiplicação e aumentaram, aproximadamente, 5 ciclos logarítmicos quando incubados às três temperaturas, após um período de dez dias.

Estes resultados foram semelhantes aos relatados por Pinto et al. (2014) que observaram o aumento da multiplicação $P$. fluorescens $07 \mathrm{~A}$ e 041 em LDR às temperaturas de refrigeração proporcional ao incremento da temperatura de incubação. Santos et al. (2013) também avaliaram a multiplicação de microrganismos psicrotróficos em amostras de leite cru refrigerado quando armazenadas por 96 horas às temperaturas de 4,7 e $10^{\circ} \mathrm{C}$ e resultados similares aos reportados pelo presente trabalho foram verificados. Izidoro et al. (2013) também constataram aumento significativo da microbiota psicrotrófica em amostras de leite refrigerado de acordo com o aumento da temperatura e do tempo de estocagem.

A $4{ }^{\circ} \mathrm{C}$, os isolados $07 \mathrm{~A}$ e 041 atingiram uma população de $10^{8} \mathrm{UFC} / \mathrm{mL}$, em sete dias de estocagem, o que correspondeu a um aumento de quatro ciclos logarítmicos. No décimo dia já havia contagem de, aproximadamente, $10^{9} \mathrm{UFC} / \mathrm{mL}$. Resultados semelhantes foram reportados por Pinto et al. (2014) que constataram um aumento de 4 ciclos Log do isolado 07A e 041 após 8 e 6 dias de estocagem, respectivamente. Esses resultados demonstram que, a temperatura de $4{ }^{\circ} \mathrm{C}$ exigida pela legislação para a conservação do leite na propriedade rural não é suficiente para conservar a qualidade microbiológica do leite dependendo da contaminação inicial da matéria prima a ser refrigerada e do período em que o leite fique submetido a esta condição. Por isso, ressalta-se a importância de manter o leite cru em período não superior às $48 \mathrm{~h}$ após a ordenha. Com isso, espera-se que haja cumprimento à nova regra da IN 76/2018 que fixou um padrão microbiológico do leite cru na propriedade rural e também estabeleceu padrão microbiológico do leite na indústria antes de ser processado, o que não havia obrigatoriedade na IN 62/2011.

Santos et al. (2008) observaram períodos de armazenamento do leite superiores a 48 horas e ressaltaram que a pequena produção de leite em algumas propriedades torna difícil a programação da coleta no período recomendado pela legislação. Como há multiplicação de microrganismos psicrotróficos sob condições de refrigeração, um período máximo de estocagem deve ser utilizado como parâmetro de identidade e qualidade para o leite cru refrigerado. Além disso, muitas pesquisas já demonstraram que a temperatura de $4{ }^{\circ} \mathrm{C}$ é mais adequada para a conservação da qualidade microbiológica do leite quando comparada às temperaturas de 7 e $10^{\circ} \mathrm{C}$ (MACHADO et al., 2013; SANTOS et al., 2013; PERIN et al., 2012; BERSOT et al., 2010; NÖRBERG et al., 2010). Nörberg et al. (2010) demonstraram que a redução da temperatura de armazenamento de $7^{\circ} \mathrm{C}$ para $2{ }^{\circ} \mathrm{C}$ permitiu reduzir a multiplicação de psicrotróficos, bem como a atividade proteolítica desses microrganismos.

A uma temperatura de $7^{\circ} \mathrm{C}$, os isolados atingiram um número de células de, aproximadamente, $10^{8} \mathrm{UFC} / \mathrm{mL}$ em sete dias, correspondendo a um aumento de quatro ciclos logarítmicos. No trabalho realizado por Pinto et al. (2014), o aumento de 4 ciclos Log dos isolados $07 \mathrm{~A}$ e 041 foi verificado após 4 e 5 dias de estocagem, respectivamente. Machado 
et al. (2013), ao avaliarem a multiplicação de psicrotróficos e de $P$. fluorescens em leite cru refrigerado, observaram um aumento expressivo dessa estirpe após 4 dias de estocagem a $7{ }^{\circ} \mathrm{C}$. A contagem inicial de $7,0 \times 10$ $\mathrm{UFC} / \mathrm{mL}$ alcançou $2,4 \times 10^{7} \mathrm{UFC} / \mathrm{mL}$, o que mostra um aumento de 6 ciclos logarítmicos após o período de refrigeração. A população de psicrotróficos contaminantes da amostra aumentou de $3,2 \times 10^{3} \mathrm{UFC} / \mathrm{mL}$ para $3,0 \times 10^{8} \mathrm{UFC} / \mathrm{mL}$ no mesmo período de armazenagem.

É importante destacar a alteração da IN 62/2011 que admitia que o leite fosse armazenado a $7{ }^{\circ} \mathrm{C}$ na propriedade rural e entregue na indústria para o processamento a temperatura máxima de $10^{\circ} \mathrm{C}$ (BRASIL, 2011). Atualmente, segundo as IN 76/2018 (BRASIL, 2018a) e a IN 77/2018 (BRASIL, 2018b), o leite deverá ser armazenado a $4{ }^{\circ} \mathrm{C}$ no tanque de expansão e recebido na indústria a temperatura máxima de $7{ }^{\circ} \mathrm{C}$, podendo, excepcionalmente, ser recebido a $9{ }^{\circ} \mathrm{C}$.

No estabelecimento industrial, antes do processamento, o leite cru deverá ser armazenado a temperatura de até $4{ }^{\circ} \mathrm{C}$. O tempo de armazenamento deverá ser determinado em função da sua contaminação inicial e das boas práticas empregadas na sua obtenção, armazenamento e transporte uma vez que o leite, antes do processamento deverá ter uma contagem padrão em placas de no máximo 900.000 UFC/mL (BRASIL, 2018a). Por isso, ressalta-se que o leite deve ser obtido em condições higiênico-sanitárias adequadas para diminuir a contaminação inicial e, desta forma, poderia manter a contagem microbiana em níveis baixos, além da sua manutenção no tempo e temperaturas adequados, conforme determina a legislação.

À temperatura de $10{ }^{\circ} \mathrm{C}$, uma concentração de $10^{9} \mathrm{UFC} / \mathrm{mL}$ foi constatada para os isolados 07A com oito dias de estocagem, enquanto o isolado 041 apresentou esta contagem com sete dias, o que correspondeu a um aumento de cinco ciclos logarítmicos. Este resultado também foi relatado por Pinto et al. (2014) que observaram aumento de 5 ciclos Log desses isolados após 7 dias de armazenamento.

Santos et al. (2010) obtiveram resultados semelhantes com a inoculação de $P$. fluorescens em leite in vitro. Foi realizado o monitoramento da multiplicação nas temperaturas de 4,7 e $10{ }^{\circ} \mathrm{C}$ por 120 horas e observado um comportamento muito semelhante do microrganismo nas três temperaturas avaliadas. Bersot et al. (2010) quantificaram microrganismos psicrotróficos e psicrotróficos proteolíticos ao longo do transporte granelizado e observaram que a refrigeração na propriedade e seu transporte em caminhão isotérmico não foram suficientes para o controle da multiplicação destes microrganismos. Dessa forma, se o leite cru é submetido a períodos de estocagem prolongados sob refrigeração, o controle de psicrotróficos na matéria prima é extremamente importante, pois a sua multiplicação, com consequente atividade enzimática, pode ocasionar problemas tecnológicos e comprometer a qualidade e a vida de prateleira de seus derivados.

\section{Avaliação da atividade proteolítica dos isolados de P. fluorescens 07A e $041 \mathrm{em}$ ágar-leite}

A avaliação da atividade proteolítica dos isolados $07 \mathrm{~A}$ e $041 \mathrm{em}$ meio de cultura foi verificada pela formação de halo, em ágarleite, nas temperaturas de 21 e $7^{\circ} \mathrm{C}$, conforme serão apresentado nas Figura 3 e 4.

De acordo com os resultados, foi possível evidenciar a atividade proteolítica dos isolados pelo surgimento de um halo translúcido ao redor de cada colônia, em decorrência da hidrólise da caseína presente no meio utilizado. Essa metodologia é amplamente empregada para evidenciar o potencial proteolítico de isolados psicrotróficos do leite refrigerado 
(SAMET-BALI et al., 2013; ZHANG; LV, 2014; MAHROUS; MOUSA, 2012; PERIN et al., 2012; NÖRBERG et al., 2010). O isolado $07 \mathrm{~A}$ apresentou maior atividade proteolítica à temperatura de $7{ }^{\circ} \mathrm{C}$ quando comparado ao isolado 041, devido ao tamanho do halo ser maior ao redor da colônia. Resultados distintos foram reportados por Martins et al. (2015) que detectaram maior atividade proteolítica do isolado 041 em relação ao 07A, quando cultivados em LDR $12 \%$ após incubação da $25^{\circ} \mathrm{C}$ por $18 \mathrm{~h}$. Esses resultados podem ser em decorrência das diferenças de condições de cultivos dos microrganismos realizadas em cada estudo.

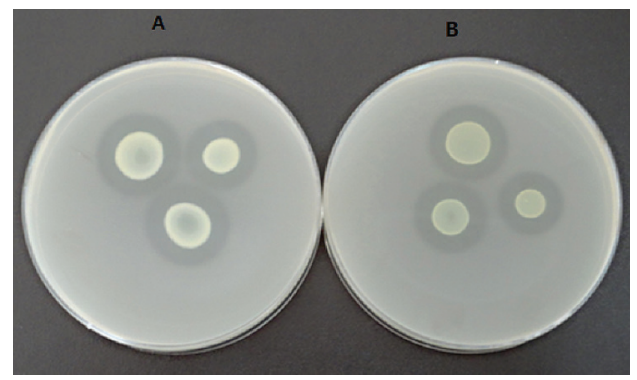

Figura 3 - Multiplicação dos isolados de $P$. fluorescens 07A (A) e P. fluorescens 041 (B) à temperatura de $21^{\circ} \mathrm{C} / 24 \mathrm{~h}$

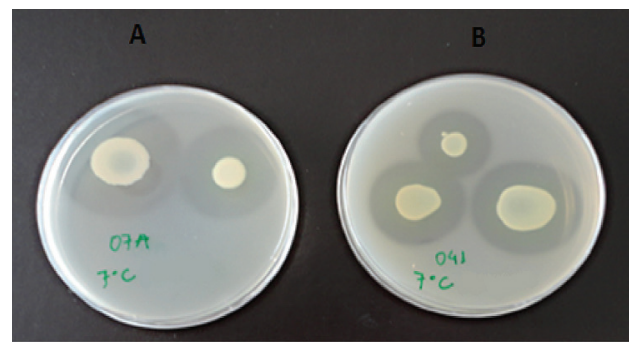

Figura 4 - Multiplicação dos isolados de $P$. fluorescens 07A (A) e P. fluorescens 041 (B) à temperatura de $7{ }^{\circ} \mathrm{C} / 10$ dias.

O controle da multiplicação de bactérias psicrotróficas tem fundamental importância no prolongamento de vida de prateleira do leite e de seus derivados. O aumento do número de psicrotróficos proteolíticos depende do tempo de estocagem do leite cru refrigerado e pode levar a um aumento da proteólise no leite (MACHADO et al., 2013; ZENI et al., 2013; PERIN et al., 2012). Dessa forma, as bactérias psicrotróficas proteolíticas podem afetar a qualidade de diversos produtos lácteos (MACHADO et al., 2013; ZENI et al., 2013; SAMARŽIJA et al., 2012).

\section{Avaliação da atividade proteolítica dos isolados de P. fluorescens 07A e $041 \mathrm{em}$ azocaseína}

Os resultados da avaliação da atividade proteolítica dos isolados em azocaseína estão apresentados na Tabela 1.

De acordo com os resultados apresentados na Tabela 1, é possível verificar o potencial proteolítico dos isolados e que houve diferença estatística entre eles, sendo que o isolado 07A superou o 041 e este último superou o controle $(\mathrm{p}<0,05)$. Portanto, o isolado 07A apresentou maior atividade proteolítica quando comparada à $P$. fluorescens 041 , o que também foi observado pela maior formação do halo em ágar leite, conforme relatado anteriormente.

Pinto et al. (2010) avaliaram a atividade proteolítica do isolado $P$. fluorescens 07A usando azocaseína como substrato e a associaram com a densidade populacional. A atividade proteolítica foi detectada quando a concentração de célula foi maior que $10^{8} \mathrm{UFC/}$ $\mathrm{mL}$, o que indica que a produção de protease poderia estar relacionada com a densidade populacional quando as bactérias atingem a fase estacionária de multiplicação. Nicodème et al. (2005) também obtiveram resultados semelhantes entre isolados de P. fluorescens, pois verificaram que a atividade proteolítica foi detectada no meio da fase Log e durante a fase estacionária de multiplicação das estirpes avaliadas. 
Tabela 1 - Atividade proteolítica dos isolados de P. fluorescens 07A e 041 ( \pm desvio padrão)

\begin{tabular}{cccc}
\hline Microrganismo & P. fluorescens 7A & P. fluorescens $041^{\text {Controle** }}$ & Con $^{*}$ \\
\hline $\begin{array}{c}\text { Atividade Proteolítica } \\
\mathrm{U} / \mathrm{mL}( \pm \mathrm{DP}){ }^{*}\end{array}$ & $52( \pm 2,77)^{\mathrm{a}}$ & $31( \pm 1,924)^{\mathrm{b}}$ & $3( \pm 0,548)^{\mathrm{c}}$ \\
\hline
\end{tabular}

* Letras iguais indicam valores semelhantes pelo teste de Tukey ao nível de 5\% de probabilidade.

$\mathrm{DP}=$ desvio-padrão

** Controle: meio mineral sem inóculo bacteriano

A diferença da atividade proteolítica detectada entre os dois isolados, no presente estudo, pode ser explicada pela grande diversidade genética e expressão de proteases entre os microrganismos psicrotróficos, principalmente entre as espécies do gênero Pseudomonas (HE et al., 2009; MARTINS et al., 2006; DOGAN; BOOR, 2003). Dufour et al. (2008) também avaliaram a atividade proteolítica entre isolados do grupo Pseudomonas usando azocaseína e constaram que houve grande diversidade no grau da atividade proteolítica entre eles e atribuíram este resultado em decorrência da heterogeneidade na expressão das enzimas proteolíticas.

\section{CONCLUSÕES}

A multiplicação das estirpes psicrotróficas $P$. fluorescens $07 \mathrm{~A}$ e $041 \mathrm{em}$ diferentes temperaturas de refrigeração foi constatada, sendo que houve aumento da multiplicação proporcional ao acréscimo da temperatura e do período de estocagem, o que reflete a realidade das condições de armazenamento do leite no Brasil. Portanto, se o leite cru é submetido a períodos de estocagem prolongados sob refrigeração, o controle dos microrganismos psicrotróficos é importante para não afetar a sua qualidade.

A avaliação da atividade proteolítica dos isolados demonstrou o seu potencial deteriorador, sendo que o isolado 07A apresentou-se mais proteolítico do que o 041 devido à variabilidade genética e expressão das proteases entre as estirpes do gênero Pseudomonas. Tendo em vista que as temperaturas estabelecidas pela legislação não inibem a multiplicação e nem a atividade enzimática desses microrganismos, é necessário que haja adoção de boas práticas de produção do leite para evitar a sua contaminação, uma vez que esses microrganismos são capazes de produzir proteases termoestáveis que reduzem a qualidade do leite e comprometem a produção de derivados, o que causa prejuízos à indústria laticinista.

\section{AGRADECIMENTOS}

Aos pesquisadores da EPAMIG e da EMBRAPA envolvidos na pesquisa. À FAPEMIG pelo financiamento do projeto e pela concessão das bolsas PCRH, BIPDT e PIBIC.

\section{REFERÊNCIAS}

BAGLINIÈRE, F.; MATÉOS, A.; TANGUY, G.; JARDIN, J.; BRIARD-BION, V.; ROSSEUAU, F.; ROBERT, B.; BEAUCHER, E.; GAILLARD J. L.; AMIEL, C.; HUMBERT, G.; DARY, A. Proteolysis of ultra high temperature-treated casein micelles by APRX enzyme from Pseudomonas fluorescens F induces their destabilization. International Dairy Journal, v. 31, p. 55-61, 2013. 
BAGLINIÈRE, F.; TANGUY, G.; JARDIN, J.; MATÉOS, A.; BRIARD, V.; ROSSEAU, F.; ROBERT, B.; BEAUCHER, E.; HUMBERT, G.; DARY, A.; GAILLARD, J. L.; AMIEL, C.; GAUCHERON, F. Quantitative and qualitative variability of caseinolytic potential of different strains of Pseudomonas fluorescens: implications for the stability of casein micelles of UHT milks during their storage. Food Chemistry, v. 135, p. 2593-2603, 2012.

BERSOT, L. S.; PEREIRA, J. G.; ZANETTE, C. M.; PIEROZAN, E. A.; MAZIERO, M. T. Quantificação de microrganismos indicadores de qualidade em leite cru e comportamento da microbiota ao longo do transporte. Revista do Instituto de Laticínios Cândido Tostes, $\mathrm{n}$. 373, v. 65, p. 9-13, 2010.

BRASIL. Ministério da Agricultura Pecuária e Abastecimento. Instrução Normativa $n^{\circ} 76$. Aprova os Regulamentos Técnicos que fixam a identidade e as características de qualidade que devem apresentar o leite cru refrigerado, o leite pasteurizado e leite tipo A. Diário Oficial da União, Brasília, DF, 26 nov. $2018 \mathrm{a}$.

BRASIL. Ministério da Agricultura Pecuária e Abastecimento. Instrução Normativa $n^{\circ} 77$. Critérios e procedimentos para a produção, acondicionamento, conservação, transporte, seleção e recepção de leite cru. Diário Oficial da União, Brasília, DF, 26 nov. 2018 b.

BRASIL. Ministério da Agricultura Pecuária e Abastecimento. Instrução Normativa $n^{\circ}$ 62. Regulamentos técnicos da produção, identidade, qualidade do leite tipo A, leite cru refrigerado e leite pasteurizado. Diário Oficial da União, Brasília, DF, 29 dez. 2011.

BRASIL. Ministério da Agricultura Pecuária e Abastecimento. Instrução Normativa $n^{\circ}$ 51. Regulamentos técnicos da produção, identidade, qualidade, coleta e transporte de leite. Diário Oficial da União, Brasília, DF, 18 set. 2002 .

DOGAN, B.; BOOR, K. J. Genetic diversity and spoilage potentials among Pseudomonas spp. isolated from fluid milk products and dairy processing plants. Applied and Environmental Microbiology, v.69, p.130138, 2003.

DUFOUR, D.; NICODÈME, M.; PERRIN, C.; DRIOU, A.; BRUSSEAUX, E.; HUMBERT, G.; GAILLARD, J. L.; DARY, A. Molecular typing of industrial strains of Pseudomonas ssp. isolated from milk and genetical and biochemical characterization of an extracellular protease produced by one of them. International Journal of Food Microbiology, v. 125, p. 188-196, 2008.

HE, H.; DONG, J.; LEE, C. N.; LI, Y. Molecular analysis of spoilage-related bacteria in pasteurized milk during refrigeration by PCR and denaturing gradient gel. Journal of Food Protection, v. 72, n.3, p.572-577, 2009.

IZIDORO, T. B.; PEREIRA, J. G.; SOARES, V. M.; SPINA, T. L. B; PINTO, J. P. A. N. Atividade proteolítica de bactérias psicrotróficas em leites estocados em diferentes temperaturas. Revista Ceres, Viçosa, v. 60, n. 4, p. 452-457, 2013.

MACHADO, S. G.; BAZZOLLI, D. M. S; VANETTI, M. C. D. Development of a PCR method for detecting proteolytic psychrotrophic bacteria in raw milk. International Dairy Journal, v. 29, p. 8-14, 2013.

MAHROUS, H.; MOUSA, I. Proteolytic and lipolytic activities of Pseudomonas spp isolated from pasteurized milk. African Journal of Food Science, v. 6, n. 6, p. 159$162,2012$. 
MARTINS, M. L.; PINTO, U. M.; RIEDEL, K.; VANETTI, M. C. D. Milk-deteriorating exoenzymes from Pseudomonas fluorescens 041. Brazilian Journal of Microbiology, v. 46, n. 1 , p. $2017-217,2015$

MARTINS, M. L.; PINTO, C. L. O.; ROCHA, R. B.; ARAÚJO, E. F.; VANETTI, M. C. D. Genetic diversity of Gram-negative, proteolytic, psycrotrophic bacteria isolated from refrigerated raw milk. International Journal of Food Microbiology, v. 111, p. 144-148, 2006.

NICODÈME, M.; GRILL, J. P.; GAILLARD, H.; GAILLARD, J. L. Extracellular protease activity of different Pseudomonas strain: dependence of proteolytic activity on culture conditions. Journal of Applied Microbiology, v. 99, p. 641-648, 2005.

NÖRBERG, M. F. B. L.; FRIEDERICH, R. S. C.; WEISS, R. D. N.; TONDO, E. C.; BRANDELLI, A. Proteolytic activity among psychrotrophic bacteria isolated from refrigerated raw milk. International Journal of Dairy Science, v. 63, n. 1, p. 41-46, 2010 .

NÖRBERG, M. F. B. L., TONDO, E. C., BRANDELLI, A. Bactérias psicrotróficas e atividade proteolítica no leite cru refrigerado. Acta Scientiae Veterinariae, v. 37, n. 2, p. 157-163, 2009.

PERIN, L. M; MORAES, P. M.; ALMEIDA, M. V.; NERO, L. A. Interferência de temperaturas de estocagem no desenvolvimento da microbiota mesófila, psicrotrófica, lipolítica e proteolítica de leite cru. Semina: Ciências Agrárias, v. 33, n. 1, p. 333-342, 2012.

PINTO, U. M.; COSTA, E. D.; MANTOVANI, H. C.; VANETTI, M. C. D. The proteolytic activity of Pseudomonas fluorescens 07A isolated from milk is not regulated by quorum sensing signals. Brazilian Journal of Microbiology, v. 41, p. 91-96, 2010.

PINTO, C. L. O.; MACHADO, S. G.; CARDOSO, R. R.; VANETTI, M. C. D. Sedimentação, atividade proteolítica e proteólise de leite UHT integral durante o armazenamento. Revista do Instituto de Laticínios Cândido Tostes, v. 71, n. 4, p. 197 205, 2016.

PINTO, C. L. O.; MACHADO, S. G.; CARDOSO, R. R.; ALVES, R. M.; VANETTI, M. C. D. Proteolytic potencial of Pseudomonas fluorescens isolated from refrigerated raw milk. Revista Brasileira de Agropecuária Sustentável (RBRAS), v. 4, n. 2, p. 16-25, 2014.

PINTO, C. L. O. Bactérias psicrotróficas proteolíticas do leite cru resfriado granelizado usado para produção de leite UHT. Viçosa, MG: UFV, Tese (Doutorado em Microbiologia Agrícola) - Universidade Federal de Viçosa, 2004, 97p.

RAAS, D.; OFFEK, M.; MINIZ, D.; HALPERN, M. Molecular analysis of bacterial communitites in raw cow milk and the impact of refrigeration on its structure and dynamics. Food Microbiology, v. 28, p. 465-471, 2011.

SAMARŽIJA，D.; ZAMBERLIN，S.; POGACIC, T. Psychrotrophic bacteria and milk and dairy products quality. Mljekarstvo, v. 62, n. 2, p. 77-95, 2012.

SAMETI-BALI, O.; FELFOUL, I.; LAJNAF, R.; ATTIA, H.; AYADI, M. A. Study of proteolytic and lipolytic activities of $\mathrm{Pseu}$ domonas spp. isolated from pasteurized milk in Tunisia. Journal of Agricultural Science, v. 5, n. 7, p. 76-50, 2013. 
SANTOS, A. S.; PIRES, C. V.; SANTOS, J. M.; COSTA SOBRINHO, P. S. C. Crescimento de micro-organismos psicrotróficos em leite cru refrigerado. Alimentos e Nutrição, v. 24, n. 3, p. 297-300, 2013.

SANTOS, P. A.; SILVA, M. A. P.; ANASTÁCIO, P. I. B.; SILVA JÚNIOR, L. C.; ISEPON, J. S.; NICOLAU, E. S. Qualidade do leite cru refrigerado estocado por diferentes períodos. Revista do Instituto de Laticínios Cândido Tostes, n. 364, v. 63, p. 36-41, 2008.

SANTOS, P. A.; SILVA, M. A. P.; MOREIRA, G. N.; BARROS, J. C.; OLIVEIRA, A. N.; NICOLAU, E. S. Evolução da proteólise do leite inoculado in vitro com Pseudomonas fluorescens. Boletim CEPPA, Curitiba, v. 28, n. 2, p. 313-320, 2010.

SILVA, N.; JUNQUEIRA, V. C.A.; SILVEIRA, N. F. A.; TANIWAKI, M. H.; SANTOS, R. F.
S.; GOMES, R. A. R. Manual de Métodos de Análise Microbiológica de Alimentos. $3^{\mathrm{a}} \mathrm{ed}$. São Paulo: Editora Varela, p. 137-148, 2007.

S ØRHAUG， T.; S T EPANIAK, L. Psychrotrophics and their enzymes in milk and dairy products: Quality aspects. Trends in Food Science \& Technology, v. 8, p. 3540, 1997.

ZENI, M. P.; MARAN, M. H. S.; SILVA, G. P. R.; CARLI, E. M.; PALEZI, S. C. Influência dos microrganismos psicrotróficos sobre a qualidade do leite refrigerado para produção de UHT. Unoesc \& Ciência-ACET, v. 4, n. 1, p. 61-70, 2013.

ZHANG, S.; LV, J. Purification and proprieties of heat-stable extracellular protease from Pseudomonas fluorescens BJ-10. Journal of Food Science and Technology, v. 51, n. 6, p. 1185-1190, 2014. 